\title{
The Effect of n-6 Polyunsaturated Fatty Acid on Blood Levels of Malondialdehyde-Deoxyguanosine Adducts in Human Subjects
}

\author{
S.A. Moore ${ }^{*, 1,2}$, E. Humphreys ${ }^{3}$, M.D. Friesen ${ }^{4}$, D.E.G. Shuker ${ }^{2}$ and S.A. Bingham ${ }^{3}$ \\ ${ }^{I}$ School of Pharmacy and Biomolecular Sciences, Liverpool John Moores University, Liverpool, UK \\ ${ }^{2}$ Department of Chemistry and Analytical Sciences, The Open University, Walton Hall, Milton Keynes, UK \\ ${ }^{3}$ Dunn Human Nutrition Unit, Wellcome Trust/Medical Research Council Building, Cambridge, UK \\ ${ }^{4}$ IARC, Lyon, France; Current address: Johns Hopkins Bloomberg School of Public Health, Department of Environ- \\ mental Health Sciences, Baltimore, MD, USA
}

\begin{abstract}
The role of $n-6$ polyunsaturated fats upon the formation of the mutagenic DNA adduct malondialdehydedeoxyguanosine $\left(\mathrm{M}_{1} \mathrm{dG}\right)$ in blood was investigated in male volunteers $(n=13)$ who consumed diets high in saturated and polyunsaturated fats, and polyunsaturated fat plus $a$-tocopherol supplemention (400 IU per day). On day 14 there was a significant difference in adduct levels between diets with saturated fats giving higher levels than polyunsaturated fats but this effect had disappeared by day 20 indicating that there is a relatively rapid adjustment to the effects on DNA damage of changes in dietary fat. $a$-Tocopherol showed a small benefit by day 20 . Five females participated in the PUFA study and had higher mean adduct levels than men but there was no correlation with hormonal status. Overall, PUFA had a limited beneficial effect on $\mathrm{M}_{1} \mathrm{dG}$ levels that warrants further investigation.
\end{abstract}

\section{INTRODUCTION}

There is a vast body of evidence, from both epidemiological and dietary intervention studies [1-3], suggesting that diet is an important factor with regard to many health problems including the incidence of many cancers, although identification of the most important aspects are often elusive. There is, however, known to be a large geographical difference in the incidence of colorectal cancer with the highest number of cases in western countries such as Europe and the USA, whilst studies in migrant populations have shown that colorectal cancer incidence increases upon changing to a western diet [4-6], although changes in other lifestyle factors such as physical activity levels have also been implicated. Dietary fat, lipid peroxidation (LPO) and arachidonic acid metabolism have all been linked, amongst other factors, to colorectal carcinogenesis in a number of studies [7-9]. LPO is initiated by the attack of free-radicals on membrane lipids leading to reactive products that may be linked to tumour initiation. Malondialdehyde (MDA) is known to be a major product of LPO and has been shown to be mutagenic in bacterial $[10,11]$ and mammalian cells [12] due to the formation of the malondialdehyde-deoxyguanosine adduct, $\mathrm{M}_{1} \mathrm{dG}$ [13]. We have previously shown that inflammation of the gut is directly linked to elevated levels of $\mathrm{M}_{1} \mathrm{dG}$ [14]. Another study has suggested that a diet high in $n-6$ polyunsaturated fatty acids (PUFA) elevates $\mathrm{M}_{1} \mathrm{dG}$ adducts in human blood DNA, with women showing a slighter higher increase than men, [15] compared with a diet rich in monounsaturated fats. Nair et al. [16] examined etheno adducts in a subset of these

*Address correspondence to this author at the School of Pharmacy and Biomolecular Sciences, Liverpool John Moores University, Byrom Street, Liverpool, L3 3AF, UK; Tel: 0044 (0) 151231 2049; Fax: 0044 (0) 151231 2170; E-mail: s.a.moore@ljmu.ac.uk volunteers and found greatly elevated etheno adduct levels in the women only. Thus, the authors of these two studies concluded that $n$-6 PUFA could increase LPO-derived DNA adducts in vivo with women showing the highest levels. However, we have previously shown that there is a large inter-individual variation in $\mathrm{M}_{1} \mathrm{dG}$ adduct levels in human colorectal mucosa of free-living adults and that in women $\mathrm{M}_{1} \mathrm{dG}$ adduct levels were positively associated with saturated fat (SFA), rather than PUFA [17]. Furthermore, the $\mathrm{M}_{1} \mathrm{dG}$ adducts showed an inverse association with both PUFA: SFA and monounsaturated fatty acids: SFA ratios. Thus, our epidemiological studies appear to be contradictory to the intervention studies of other researchers and we decided to examine this further in a carefully controlled intervention study. The analysis of blood samples was carried out primarily as a direct comparison to previous studies but also to investigate the potential of utilising $\mathrm{M}_{1} \mathrm{dG}$ as a biomarker of colorectal cancer risk. We had previously determined that the $\mathrm{M}_{1} \mathrm{dG}$ adduct is stable in frozen blood and tissue samples and therefore suitable for long-term storage prior to analysis (unpublished data) making it a good candidate for large scale studies such as the EPIC cohort [18] where analyses may be performed many years after the samples have been collected.

In this study, male volunteers undertook a randomized cross-over intervention that was designed to further explore the effect of dietary PUFA compared with SFA and to modify any increase in $\mathrm{M}_{1} \mathrm{dG}$ in WBC DNA by supplementation with $a$-tocopherol, a fat soluble anti-oxidant that is present in plasma and gastric mucosa in equivalent concentrations [19]. $a$-Tocopherol would be expected to reduce lipid peroxidation by reducing free radicals, and ultimately $\mathrm{M}_{1} \mathrm{dG}$. To further investigate the hypothesis that the formation of $\mathrm{M}_{1} \mathrm{dG}$ is related to hormonal status, [20] 5 premenopausal women not taking the contraceptive pill undertook the PUFA diet only 
in order to identify any patterns in $\mathrm{M}_{1} \mathrm{dG}$ levels throughout their menstrual cycles that might be worthy of further consideration. Both of these studies were carried out in a metabolic suite where diet was carefully controlled.

\section{MATERIALS AND METHODS}

\section{Materials}

Tetramethoxypropane (TMP), guanine, calf thymus DNA (CT-DNA), propidium iodide (PI), were obtained from Sigma Chemical Co. Ltd. (Dorset, UK). Human genomic DNA (1691112) was purchased from Boehringer Mannheim (Lewes, UK). Phosphate buffered saline (PBS) tablets were purchased from Oxoid Ltd. (Basingstoke, Hampshire, UK). QIAGEN genomic-tips 100/G were purchased from Qiagen Ltd. (Crawley, UK), $0.45 \mu \mathrm{m}$ nitrocellulose (NC) membrane (BA85) and Minifold II, 72 well slot blot microfiltration apparatus were purchased from Schleicher \& Schuell (Dassel, Germany), goat anti-mouse IgG horseradish peroxidase conjugate from Dako (Glostrup, Denmark) and SuperSignal Ultra from Perbio Science UK Ltd. (Cramlington, UK). All other reagents and solvents were obtained from Fisher Scientific, (Loughborough, UK), including methanol which was HPLC grade, or Sigma-Aldrich Company Ltd. (Gillingham, UK).

\section{Volunteer Protocol}

13 male and 5 female volunteers were housed in the metabolic suite of the MRC Dunn Human Nutrition Unit for the duration of each intervention but resumed their normal diets for the washout periods. The volunteers were asked to continue their usual exercise habits. All volunteers were aged $>25$ yrs old, non-smokers with no history of medical problems. Permission for these studies was given by the Cambridge Local Research Ethics Committee (LREC01/055). All specimens were collected following general protocols described elsewhere [21].

\section{Diets}

The male subjects undertook a randomised crossover intervention study consisting of three dietary periods of 20 days with a washout period of 21 days between rounds. They were fed normal foods on carefully controlled isocaloric diets that were matched for macronutrient composition. The nutritional content of each of the diets was calculated using Dietplan version 5 (for Windows) and contained 40\% total energy as fat, typical of western diets consisting of 1) $20 \%$ total energy as SFA + 5\% total energy as PUFA, 2) $20 \%$ total energy as PUFA and 5\% total energy as SFA 3) $20 \%$ total energy as PUFA and 5\% total energy as SFA plus 400 IU $\alpha$-tocopherol per day. The remaining $15 \%$ was monounsaturated fats which were kept constant throughout the diets. Food was purchased and prepared in batches and frozen to minimise variation. The basal diets were prepared to provide $10 \mathrm{MJ}$ of energy daily, with $1 \mathrm{MJ}$ increments to adjust to the needs of each individual, using standard calculations based on weight and height for required energy intakes to calculate basal metabolic weight $\times$ estimated physical activity ratio [22]. The $1 \mathrm{MJ}$ increments were provided as Polycal solution (Nutricia, Wiltshire, UK.), bread, jam and margarine or butter. Only food and drinks provided by the unit were permitted and subjects were required to consume everything provided each day. The volunteers continued with their usual tea and coffee drinking habits using the items provided by the unit, including drinking water. Volunteer body weight was monitored daily and increments adjusted accordingly in the first week until weight was stable. The volunteers ate a 3-day rotating diet during the intervention. Duplicates of food batches were stored at $-80^{\circ} \mathrm{C}$ for analysis of MDA content. The females consumed the high PUFA diet for 20-34 days as determined by the duration of their menstrual cycles.

\section{Blood Samples}

Blood was taken from the male subjects on days 1,14 and 20 of each dietary period and from the females on day 1 , the day of LH surge as determined by the use of Clear Plan Ovulation predictor test kits (Unipath, Bedford, UK), the day after the LH surge and on the final day of the study which was determined by the length of the volunteers menstrual cycles. Blood was transferred to Vacutainer ACD whole blood tubes (BD, Oxford, UK) and stored at $-80^{\circ} \mathrm{C}$ until required. Filled blood tubes were processed as follows: 1 ) centrifugation at $1000 \mathrm{~g}$ for 10 minutes at $4^{\circ} \mathrm{C}$ and the plasma aspirated off and stored at $-80^{\circ} \mathrm{C}, 2$ ) left to clot at RT for 30 min, centrifuged at $1500 \mathrm{~g}$ for 10 minutes at $4^{\circ} \mathrm{C}$ and the serum aspirated off and stored at $-20^{\circ} \mathrm{C}, 3$ ) DNA extraction using Qiagen genomic tips according to the manufacturer's protocol with the following alterations: $3 \mathrm{ml}$ of blood was digested for $2 \mathrm{~h}$ at $50^{\circ} \mathrm{C}$ in a waterbath with $122 \mu 1$ of proteinase K (Sigma P6556; $20 \mathrm{mg} / \mathrm{ml}$ ) and $100 \mu \mathrm{l}$ heat-treated RNase A (Sigma R5503; $100 \mathrm{mg} / \mathrm{ml}$ ). The tips were rinsed with $3 \times 5 \mathrm{ml}$ buffer QC. All other steps were according to the Qiagen protocol. The DNA was dissolved in $\mathrm{H}_{2} \mathrm{O}$ and stored at $-80^{\circ} \mathrm{C}$ until analysis. The concentration measured by UV analysis, $\lambda_{\max } 260 \mathrm{~nm}$. DNA purity was assessed by UV using the 260: $280 \mathrm{~nm}$ ratio.

\section{$M_{1}$ dG Adduct Analysis}

Preparation of standard $\mathrm{M}_{1} \mathrm{dG}$-DNA and the immunoslot blot assay (ISB) were as described elsewhere [23]: Standards containing $3.5 \mu \mathrm{g}$ DNA were prepared with a final DNA concentration of $100 \mu \mathrm{g} / \mathrm{ml}$ and $0-5 \mathrm{fmol}_{\mathrm{l}} \mathrm{dG} / \mu \mathrm{g}$ DNA. Solutions of standard or human DNA samples were applied in triplicate to the NC membrane ( $1 \mu \mathrm{g}$ per well), baked at $80^{\circ} \mathrm{C}$ in a vacuum oven, incubated with the anti- $\mathrm{M}_{1} \mathrm{dG}$ monoclonal antibody D10A1 [24] (1:90,000), and then incubated with the goat anti-mouse IgG HRP $(1: 4,000)$. The membrane was washed between steps. Enzymatic activity was visualised using SuperSignal Ultra. Images were captured on a Kodak Image Station $440 \mathrm{CF}$ and the results corrected for local background. Propidium iodide staining was used to reduce, and correct for, variations in DNA binding to the nitrocellulose membrane (the major source of analytical variability). Analyses were performed in triplicate on the same blot and only the results with a SD of $<20 \%$ were included in the reported data. A human DNA QC sample (Boehringer Mannheim) was included in all blots and the results rejected if the QC had a SD of $>20 \%$ for the triplicate analyses or the QC result was > 2 SD from the mean of all the QC results. The limit of detection was 0.2 adducts per $10^{7}$ normal nucleotides [23].

\section{Food MDA Analysis}

Specific preparation of the food samples for the analysis was performed using a method of Sanchez-Escalante et al. 
[25]. MDA in food was analysed using the TBARS method [26].

\section{Plasma MDA Analysis}

A method based upon that of Therasse and Lemonner was employed [27]. Plasma was mixed with DETBA (10 $\mathrm{mM})$ in phosphate buffer $(0.1 \mathrm{M}, \mathrm{pH} 3)$, ethyl acetate added and the mixture heated to $95^{\circ} \mathrm{C}$ for $1 \mathrm{~h}$, diethyl ether added and the sample centrifuged. The aqueous layer was discarded and the organic layer evaporated under nitrogen at $40^{\circ} \mathrm{C}$ and reconstituted in methanol. Analysis was by reverse phase HPLC with fluorescence detection ( $\lambda_{\mathrm{ex}} 515 \mathrm{~nm}, \lambda_{\mathrm{em}} 553 \mathrm{~nm}$ ) using $0.1 \%$ ethanolamine in water: acetonitrile $(71: 29 \mathrm{v} / \mathrm{v})$ as the mobile phase. Only the final blood samples were analysed for the men, but all samples were analysed for the women. Samples that were below the LOD $(0.005 \mathrm{nmol} / \mathrm{L})$ were reported as $0.001 \mathrm{nmol} / \mathrm{L}$ for the purpose of statistical analyses.

\section{Plasma Phospholipid Fatty Acid Analysis}

Dietary compliance was assessed by changes in plasma phospholipids using a GC-FID method based on the addition of di-palmitoyl-D31-phosphatidylcholine internal standard to plasma prior to extraction [28].

\section{Plasma Tocopherol Analysis}

Changes in plasma $\alpha$-tocopherol and $\gamma$-tocopherol were assessed using a method based on the addition of a tocol internal standard to plasma samples [29]. $200 \mu \mathrm{l}$ plasma samples were mixed with methanol for deproteinization followed by hexane extraction. The organic solvents were removed and the isolated compounds redissolved in methanol / ethanol / hexane (88/10/2; v/v) Analysis was carried out on a HP 1100 HPLC equipped with a Photo Diode Array UV Detector, an auto injector and an Altech HS C18 column $(250 \times$
$0.46 \mathrm{~mm}$ ID; $3 \mu \mathrm{m}$ ) at a flow rate of $0.9 \mathrm{ml} / \mathrm{min}$. Separation was obtained with a step gradient: 15 min solvent A (methanol / acetonitrile / acetic acid / triethylamine (40/60/0.5/0.1, $\mathrm{v} / \mathrm{v})$ ), then $10 \mathrm{~min}$ solvent B (solvent A / dichloromethane / triethylamine (76.5/23.5/0.0235, v/v)). Chromatograms were extracted at $292 \mathrm{~nm}$ for quantification of the compounds.

\section{Oestrogen Analysis}

Estradiol, progesterone and sex hormone binding globulin (SHBG) were measured using a Perkin-Elmer Auto DELFIA $^{\circledR}$ immunoassay system with Estradiol Kit B056101, Progesterone Kit B066-101 and SHBG Kit BO70-101 respectively, using the protocol described by the manufacturer.

\section{Statistics}

Statistical analyses were performed using SPSS for Windows version 14.0. Differences in adduct levels between dietary periods were assessed by Wilcoxon signed rank tests for related samples or ANOVA for unrelated samples. Associations were assessed using Spearman rank correlation coefficient.

\section{RESULTS}

Males

Dietary compliance was assessed from changes to the plasma fatty acid profiles of the volunteers throughout each intervention. Of the 19 plasma fatty acids measured, the major ones were linoleic, arachidonic, palmitic and stearic acid which together made up $80 \%$ of the total fatty acid profile on the PUFA diet and $73 \%$ on the SFA diet. Table 1 shows that, as expected, the percentage of the PUFAs, linoleic acid and arachidonic acid, was significantly greater on the PUFA diet compared with the SFA diet, and that there was a significant increase in the saturated fatty acid, palmitic acid when the

Table 1. Plasma fatty acids (\% of total), $\alpha$-tocopherol, and MDA in final blood samples (day 20), and $\mathbf{M}_{1} \mathrm{dG}$ adducts throughout dietary interventions, in male subjects on high PUFA/high SFA and high PUFA $+\alpha$-tocopherol supplemented diets. $n<13$ where results were rejected or there was insufficient sample for all analyses. Statistical analysis was by Wilcoxon Signed Ranked tests using SPSS for Windows V.14

\begin{tabular}{|c|c|c|c|c|c|c|c|c|c|c|}
\hline \multirow{2}{*}{ Analyte } & \multicolumn{3}{|c|}{ SFA (S) } & \multicolumn{3}{|c|}{ PUFA (P) } & \multicolumn{3}{|c|}{$P+\alpha-\operatorname{Toc}(T)$} & \multirow{2}{*}{$\begin{array}{c}\text { Statistical Comparison } \\
\text { Between Diets: } Z(p) \text { Values }\end{array}$} \\
\hline & Mean & sd & $n$ & Mean & sd & $n$ & Mean & sd & $n$ & \\
\hline Linoleic acid / \% & 23.9 & 5.5 & 9 & 30.4 & 1.9 & 12 & 34.3 & 2.9 & 6 & P vs S: - $2.43(0.015)$ \\
\hline Arachidonic acid / \% & 8.5 & 3.4 & 9 & 11.0 & 2.1 & 12 & 11.9 & 2.8 & 6 & P vs S: -2.31 (0.021) \\
\hline Palmitic acid / \% & 28.2 & 1.4 & 9 & 25.4 & 1.1 & 12 & 27.8 & 1.3 & 6 & P vs S: $-2.19(0.028)$ \\
\hline$\alpha$-Tocopherol $\mu \mathrm{mol} / \mathrm{L}$ & 22.9 & 7.1 & 9 & 23.4 & 5.9 & 10 & 29.3 & 2.0 & 6 & $\begin{array}{l}\mathrm{P} v s \mathrm{~S}:-0.94(0.345) \\
\mathrm{P} v s \mathrm{~T}:-1.83(0.068)\end{array}$ \\
\hline $\mathrm{M}_{1} \mathrm{dG}$ per $10^{7}$ bases: Day 1 & 1.77 & 1.59 & 11 & 2.08 & 1.43 & 10 & 3.05 & 3.78 & 9 & $\begin{array}{l}\text { P vs S: -0.338 (0.735) } \\
\text { P vs T: }-0.845(0.398)\end{array}$ \\
\hline Range on day 1 & \multicolumn{3}{|c|}{$0.20-4.84$} & \multicolumn{3}{|c|}{$0.24-4.57$} & \multicolumn{3}{|c|}{$0.25-12.74$} & \\
\hline Day 14 & 2.19 & 1.75 & 11 & 1.63 & 1.34 & 9 & 1.99 & 1.71 & 9 & $\begin{array}{l}\mathrm{P} v s \mathrm{~S}:-2.366(0.018) \\
\mathrm{P} v s \mathrm{~T}:-2.201(0.028)\end{array}$ \\
\hline Range on day 14 & \multicolumn{3}{|c|}{$0.29-4.83$} & \multicolumn{3}{|c|}{$0.32-3.70$} & \multicolumn{3}{|c|}{$0.11-5.13$} & \\
\hline Day 20 & 1.72 & 1.52 & 11 & 1.74 & 1.51 & 10 & 1.64 & 1.34 & 10 & $\begin{array}{l}\text { P vs S: -1.01 (0.314) } \\
\text { P vs T: -0.14 (0.889) }\end{array}$ \\
\hline Range on day 20 & \multicolumn{3}{|c|}{$0.18-4.94$} & \multicolumn{3}{|c|}{$0.05-4.73$} & \multicolumn{3}{|c|}{$0.28-4.14$} & \\
\hline
\end{tabular}


volunteers were on the SFA diet. Stearic acid showed very little variation between diets (data not shown). The volunteers showed a similar plasma fatty acid profile between days 14 and 20 on each diet indicating that a steady state had been reached, whilst the initial profiles were similar across all interventions for each volunteer, indicating that the washout period had been effective. $\alpha$-Tocopherol supplementation resulted in a mean increase of $25 \%$ for plasma $\alpha$ tocopherol relative to the PUFA diet on day 20 (Table 1), although this did not reach significance, $p 0.068$. This higher level was also observed on day 14 indicating a steady state and dietary compliance, as already seen with the plasma fatty acid profiles. The difference in $\alpha$-tocopherol between the PUFA and the SFA diets was not significant $(p=0.345)$ and the levels did not change throughout these interventions as was to be expected in the absence of any supplementation.

Plasma MDA levels were measured but found to be very low with some sample concentrations at or below the LOD. Analysis of 19 samples from day 20 bloods across all interventions revealed mean MDA levels of $0.007 \pm 0.007$ $\mathrm{nmol} / \mathrm{ml}, 6$ samples were below the LOD whilst the others were only just above the LOD. Plasma MDA did show a very weak positive correlation with $\alpha$-tocopherol across all $\operatorname{diets}\left(\mathrm{r}_{\mathrm{s}}=0.296, p=0.232\right)$ but there were no significant differences for MDA between diets. Analysis of the MDA concentration in foods was carried out to confirm that there was no degradation of PUFA to MDA during preparation and showed that there was no significant difference between the foods for the PUFA and SFA diets $(4.47 \pm 1.76$ and 4.62 $\pm 0.88 \mathrm{nmol} / \mathrm{ml}$ respectively).

At least three DNA samples from all blood samples were each analysed in triplicate for $\mathrm{M}_{1} \mathrm{dG}$ adducts using the ISB assay and the results reported as a mean of all analyses (Table 1). On both the PUFA and tocopherol supplemented diets the $M_{1} \mathrm{dG}$ adducts had reduced from the baseline values between days 1 and 14 , but this reached significance for the PUFA diet only $(p=0.048)$. However, for the PUFA diet the adducts actually increased slightly between days 14 and 20 $(p=0.086)$ whereas on the tocopherol supplemented diet the adduct levels had decreased further $(p=0.110)$. The opposite trend was seen with the SFA diet, adducts increased initially but then decreased again by the end of the intervention (day $1-14 p=0.959$, day $14-20 p=0.575$ ).

In order to compare the overall effects of the diets, the adduct levels on day 20 were examined as there had been a steady state of plasma fatty acids for seven days at this point and it was thought that the adduct levels would have stabilized too. However, there was a lot of inter-individual variation in the adduct levels as seen by the ranges in Table $\mathbf{1}$ at each time point. There was no significant difference between diets for all volunteers of $\mathrm{M}_{1} \mathrm{dG}$ adducts at day 20, although the mean value for the tocopherol diet is lower than the other two diets. The individual changes are shown in Fig. (1) where it can be seen that two individuals had higher levels of adducts than the rest of the cohort across all interventions, and another individual certainly had higher levels of adducts on the PUFA diet than the majority of the cohort but, due to analytical problems, it wasn't possible to measure the adducts in his other samples. The overall trend at day 20 is that more of the volunteers showed higher adduct levels on the SFA diet than on the PUFA diet $(n=6)$ and $\alpha$-tocopherol supplementation resulted in higher levels than PUFA although not reaching the levels observed with SFA. As seen in Fig. (1), three volunteers showed the opposite trend. However, when we looked at the data for day 14 we found a significant difference between the diets with the PUFA diet giving lower adduct levels than SFA $(p=0.018)$, and the tocopherol supplementation increasing the adducts relative to PUFA in all volunteers $(p=0.028)$. These individual changes at day 14 are shown in Fig (2) where all volunteers had a lower level of adducts on the PUFA diet compared with either the SFA or tocopherol supplementation which is a more consistent pattern than for day 20 (Fig. 1). Statistical analysis for correlations did not reveal any significant correla1

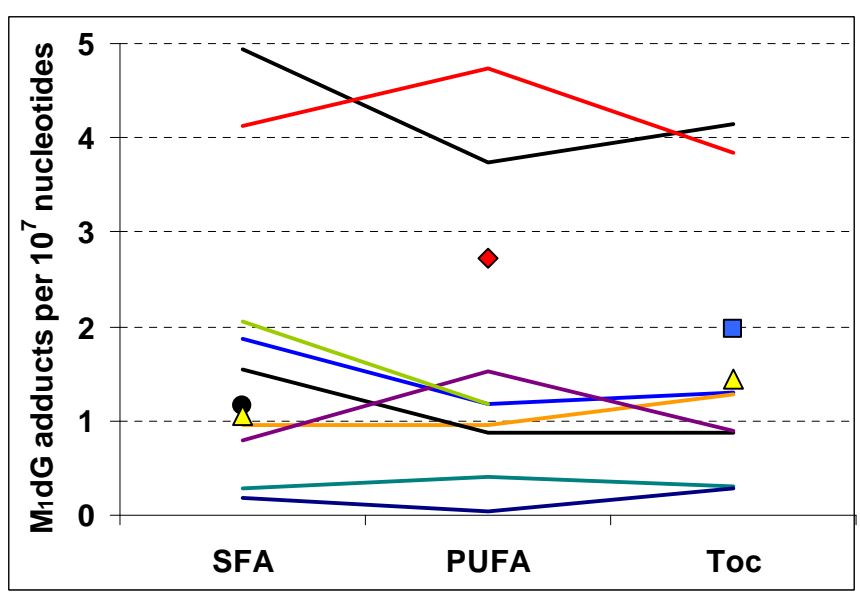

Fig. (1) $M_{1} d G$ adduct levels in WBC DNA on the final day of each diet in all volunteers $(n=13)$. A full data set is available for 8 volunteers only as shown by the lines; the remaining data is shown as single points on the graph.

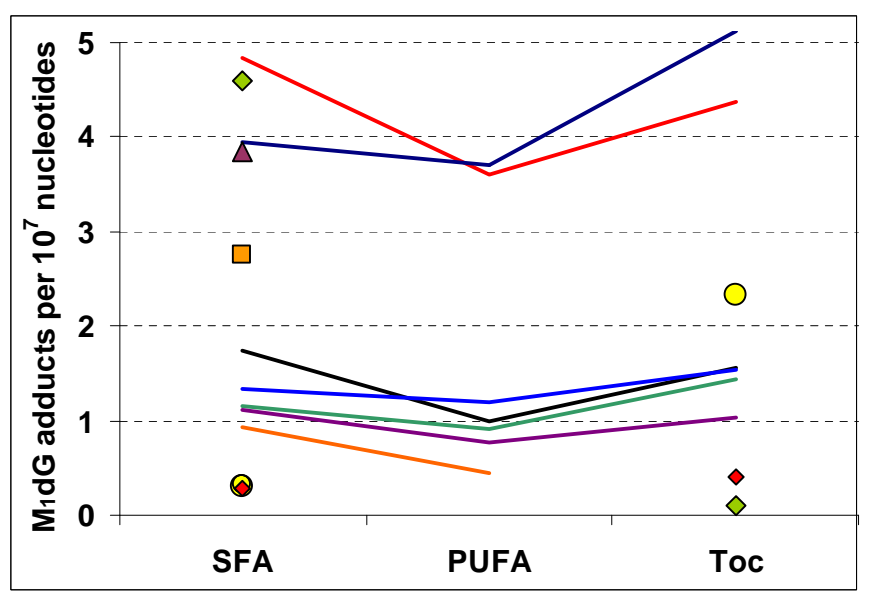

Fig. (2) $M_{1} d G$ adduct levels in WBC DNA on the day 14 of each diet in all volunteers $(n=13)$. A full data set is available for 6 volunteers only as shown by the lines; the remaining data is shown as single points on the graph.

\section{Women}

Dietary compliance in the women was also assessed by the plasma fatty acid profile throughout the intervention period (Table 2). Mean linoleic acid levels increased by $25 \%$ whereas palmitic acid and arachidonic acid decreased by $22 \%$ and $11 \%$ respectively during the study period. This 
Table 2. Results for analyses of blood samples from female subjects $(n=5)$ on high PUFA diet throughout the intervention and the statistical differences between initial and final samples by Wilcoxon Signed Ranks test using SPSS for Windows V.14

\begin{tabular}{|c|c|c|c|c|c|c|c|c|c|}
\hline Sample & & $\underset{1 \mathbf{1 0}^{7}}{\mathrm{M}_{\mathbf{1}} \mathbf{d G}}$ & $\begin{array}{c}\text { Palmitic Acid } \\
\mu \mathrm{mol} / \mathrm{L}\end{array}$ & $\begin{array}{c}\text { Linoleic } \\
\text { Acid } \mu \mathrm{mol} / \mathrm{L}\end{array}$ & $\begin{array}{l}\text { Arachidonic } \\
\text { Acid } \mu \mathrm{mol} / \mathrm{L}\end{array}$ & $\begin{array}{c}\alpha \text {-Tocopherol } \\
\mu \mathrm{mol} / \mathrm{L}\end{array}$ & $\begin{array}{c}\text { Estradiol } \\
\text { pmol/L }\end{array}$ & $\begin{array}{l}\text { SHBG } \\
\text { nmol/L }\end{array}$ & $\begin{array}{c}\text { Progesterone } \\
\text { nmol/L }\end{array}$ \\
\hline 1 & Mean & 2.19 & 1793 & 1344 & 622 & 21.02 & 143 & 132 & 2.02 \\
\hline \multirow[t]{2}{*}{2} & Mean & 2.13 & 1455 & 1655 & 600 & 24.02 & 340 & 109 & 3.28 \\
\hline & $\mathrm{sd}$ & 0.92 & 515 & 456 & 263 & 7.16 & 211 & 140 & 1.65 \\
\hline 3 & sd. & 0.71 & 104 & 333 & 125 & 2.14 & 89 & 135 & 3.65 \\
\hline \multirow[t]{2}{*}{4} & Mean & 2.70 & 1405 & 1681 & 556 & 23.11 & 130 & 136 & 3.86 \\
\hline & sd & 1.38 & 614 & 543 & 246 & 7.11 & 46 & 208 & 3.37 \\
\hline All & Mean & 2.19 & 1497 & 1554 & 576 & 22.45 & 211 & 122 & 3.34 \\
\hline$p$ & & 0.893 & 0.043 & 0.138 & 0.225 & 0.080 & 0.893 & 0.686 & 0.345 \\
\hline
\end{tabular}

change for palmitic acid was significant between day 1 and final samples $(Z=-2.023, p=0.043)$, whereas the other two fatty acids did not reach significance. The women did not, in general, exhibit a great change in mean $\mathrm{M}_{1} \mathrm{dG}$ adducts throughout the study although the third samples were the lowest overall which is a similar trend to the men. The range of adducts was 1.03-5.06 for all time points but 1.50-5.06 for the final samples only. It was thought that $\mathrm{M}_{1} \mathrm{dG}$ may be linked to the menstrual cycle but Fig. (3) shows that no trends were observed with oestradiol. Plots of MDA, sex hormone-binding globulin (SHBG) and progesterone also failed to show any trends with the variation in $\mathrm{M}_{1} \mathrm{dG}$ (data not shown).

MDA levels in women were higher than in the men with a mean value of $0.034 \pm 0.010 \mu \mathrm{mol} / \mathrm{L}$ at the end of the study, only two samples were below the LOD and there was a range of 0.007-0.081 for all samples. The data revealed a very weak negative correlation of $M_{1} \mathrm{dG}$ with $\mathrm{MDA}\left(\mathrm{R}_{\mathrm{s}}=\right.$ $0.105, p=0.745)$ and oestradiol $\left(\mathrm{R}_{\mathrm{s}}=-0.259, p=0.300\right)$, whilst MDA showed a weak negative correlation with oestradiol $\left(\mathrm{R}_{\mathrm{s}}=-0.289, p=0.362\right)$, There were no significant correlations of $\mathrm{M}_{1} \mathrm{dG}$ or MDA with any fatty acids or hormones as determined by Spearman Rank analysis (data not shown). The hormones all showed significant correlations with each other, as was to be expected, whilst SHBG and progesterone also showed a correlation with total fatty acids in the blood plasma ( $\mathrm{p}=0.042$ and 0.025 respectively) for all samples. MDA levels were low at the end of the intervention, and showed no correlation with $\mathrm{M}_{1} \mathrm{dG}$ adducts but did show a positive significant correlation with $\alpha$-tocopherol throughout the intervention $\left(\mathrm{r}_{\mathrm{s}} 0.613, \mathrm{p}=0.034\right)$, which was also observed with the men.

\section{DISCUSSION}

This study was carried out under highly controlled conditions with volunteers fed constant diets of known composi- tion. The analytical methods were all well established and the analytes were known to be stable under the storage conditions used. Changes in plasma fatty acids and $a$-tocopherol, as shown in Tables $\mathbf{1}$ and $\mathbf{2}$, verify that the volunteers kept to the diets and that the desired changes in plasma fatty acids were achieved. The normal range in UK populations of PUFA is $5.4 \pm 1.6$ (sd)\% energy, and the shift to $20 \%$ dietary fat achieved in this study was an extreme change. However, despite this, there were limited effects on plasma MDA and $\mathrm{M}_{1} \mathrm{dG}$ levels in the male subjects. In most cases MDA proved to be very low or even below the limit of detection. We had expected that a steady state of adduct levels would be reached by day 14 at the earliest and remain constant, or even show a more marked change in the same direction, until day 20. The data shows that whilst a steady state was maintained throughout this period for the plasma fatty acids, the levels of adducts was significantly different between diets on day 14 and had continued to change but reverted back towards the individuals' 'normal' levels by day 20 with the exception of the $a$-tocopherol supplemented diet which continued to decline. Thus, by day 20 there were no significant differences between the diets. This seems to indicate that a high PUFA diet has the effect of reducing adduct levels compared with SFA in the first two weeks but the body readjusts in the long term. The opposite effect is seen with SFA whereby adducts increase initially but then reduce by day 20 . Supplementation with $a$-tocopherol initially interferes with the reduction seen with PUFA although in the long term supplementation may be beneficial in some individuals who respond to its' effects (Figs. 1 and 2).

In women, there was a significant downward trend in palmitic acid with time, again indicating that the desired changes in diet were achieved. However the increase in plasma PUFAs were not related to changes in plasma MDA or $\mathrm{M}_{1} \mathrm{dG}$ adduct levels. Only one volunteer showed an increase in MDA and it was actually reduced in three volun- 


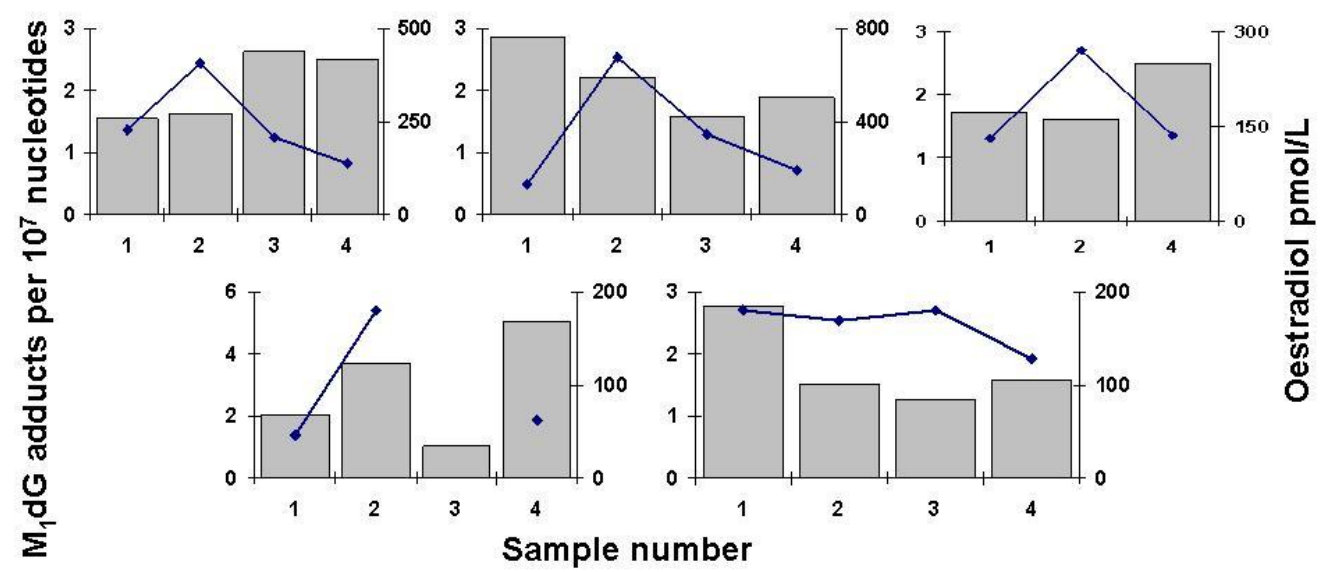

Fig. (3). Variation in $\mathrm{M}_{1} \mathrm{dG}$ adducts and oestradiol throughout the menstrual cycles in 5 volunteers (columns: $\mathrm{M}_{1} \mathrm{dG}$ adducts, $\bullet$ oestradiol).

teers. Similarly, MDA and $\mathrm{M}_{1} \mathrm{dG}$ showed no correlation with each other. An increase in MDA would be expected to correlate with an increase in $\mathrm{M}_{1} \mathrm{dG}$ but three of the volunteers showed the opposite trends for MDA and $\mathrm{M}_{1} \mathrm{dG}$. Nor was there any correlation of either MDA or $\mathrm{M}_{1} \mathrm{dG}$ with oestradiol levels throughout their menstrual cycles.

Women did have higher levels of $\mathrm{M}_{1} \mathrm{dG}$ adducts than men by the end of the PUFA intervention, as reported by Fang et al. [15], $\left(2.70\right.$ per $10^{7} \pm 1.38$ and 1.74 per $10^{7} \pm$ 1.51 ) but this was not significant (F 1.42, $p 0.26$ ). MDA levels were also higher in women $(0.034 \pm 0.010$ compared with $0.007 \pm 0.007)$ and this was significant (F $22.43 p 0.001)$. Linoleic acid in blood plasma was also generally higher in women (34\% of total fatty acids compared with $30 \%$ in men) which suggests that there may be a link in women between MDA and PUFAs such as linoleic acid.

Comparison of the data for the male volunteers does show that there was a significant difference in adduct levels at day 14 and that more than half of the volunteers showed an increase in adducts on the SFA diet compared with the PUFA diet which corroborates the study of a free-living population using dietary questionnaires [17]. This large inter-individual variation has been seen previously for many other DNA adducts, including $\mathrm{M}_{1} \mathrm{dG}$ [17, 23], and makes analysis of the data very complex. It is still not clear from our data what the link is between $\mathrm{M}_{1} \mathrm{dG}$, MDA and plasma fatty acids. Indeed, the trends seen here are the opposite of those that would be expected if $\mathrm{M}_{1} \mathrm{dG}$ is formed solely by the mechanisms discussed in the introduction.

Thus this study therefore suggests that an increase in $n-6$ PUFAs causes an initial decrease in $\mathrm{M}_{1} \mathrm{dG}$ adduct levels, which is contrary to that shown by Fang et al. [15] who compared $n-6$ PUFA and MUFA diets. We did keep MUFA constant at $15 \%$ of total energy whereas Fang et al. had differing levels on both diets (10\% on the PUFA diet and $16 \%$ on the MUFA diet). Other fats were also present in different proportions on the two studies. Consequently it may be difficult to directly make comparisons of $\mathrm{M}_{1} \mathrm{dG}$ adducts and MDA levels between the two studies. De Kok et $a l$. have also shown that $n$-6 PUFAS do not lead to high MDA or high 8-oxo-dG adduct levels, another marker of oxidative DNA damage [30], by using supplementation of the normal diet with linoleic acid and palmitic acid to alter dietary fat. It has been known for sometime that a high ratio has been known for sometime that a high ratio of $n-6: n-3$ PUFA ratio may have adverse effects [31] and more recently Davidson et al. have shown that only $n-3$ PUFAS, not $n-6$ PUFA or MUFA, are protective against DNA adduct formation and promotional stage of colon cancer in rats [32]. The Fang study utilised different ratios of $n-6: n-3$ PUFAs for the two diets (13: 0 and 3: 1 respectively) and the beneficial effect of their MUFA diet may actually be due to the lower $n$ 6: $n-3$ ratio rather than MUFA itself.

Another fact that should be considered is the length of the dietary intervention. We intended to look at the adduct levels after 20 days when a steady state of plasma fatty acids was known to exist. Analysis of the data showed that the adducts were not in a steady state case despite this being the case for the plasma fatty acids. Other researchers have looked at different intervention lengths; Fang et al. [15] had a 25 day intervention whereas de Kok et al. had a 42 day intervention [30]. Thus, the differences observed between studies may be due, in part, to the intervention length if DNA adducts are rapidly removed from the body after a certain period of time which may vary between individuals, and for different adducts.

One further option is that $\mathrm{M}_{1} \mathrm{dG}$ is not a product of the reaction of DNA with MDA from lipid peroxidation but due to the reaction with base propenals from oxidative cleavage of the DNA backbone [33]. Base propenals and MDA can both be derived from 4'-oxidation of deoxyribose although base propenals have been reported to be more mutagenic (30-60 fold) than MDA due to a more efficient reaction with DNA [34]. This may explain the reason that intracellular levels of $\mathrm{M}_{1} \mathrm{dG}$ are relatively insensitive to variations in plasma PUFA [33] although oxidation of PUFAs is known to give $\mathrm{MDA}$ and $\mathrm{M}_{1} \mathrm{dG}$ [33]. Furthermore, $\mathrm{M}_{1} \mathrm{dG}$ has been detected in urine samples at levels of $12+/-3.8 \mathrm{fmol} \mathrm{kg}^{-1}$ [35] and may also be oxidized to 6-oxo- $\mathrm{M}_{1} \mathrm{dG}$ adducts prior to excretion in urine [36, 37]. It therefore appears that analysis of $\mathrm{M}_{1} \mathrm{dG}$ from blood DNA will not be a useful biomarker of colorectal cancer risk due to rapid excision and excretion and that the analysis of $\mathrm{M}_{1} \mathrm{dG}$ adducts in urine may prove to be more beneficial. Moreover, the collection of urine samples is less invasive and simpler than the collection of blood samples making it the preferred option for use as a biomarker. 


\section{CONCLUSIONS}

The purpose of this study was to examine the effects of n-6 PUFA upon $\mathrm{M}_{1} \mathrm{dG}$ adducts. The diets were designed to reflect normal eating habits in this country with the aim of advising people upon diet with potential future consequences in relation to cancer. We found that the levels of both MDA and $\mathrm{M}_{1} \mathrm{dG}$ were very low, sometimes around the limit of detection for the assays used, particularly in the case of MDA, and that a high level of dietary $n-6$ PUFA does not significantly influence blood levels of MDA in blood plasma. However, $\mathrm{M}_{1} \mathrm{dG}$ adducts did show significant differences at day 14 of the study but not at the end indicating that the body is able to regulate these adduct levels possibly by excision and excretion via other routes. The observations corroborate those made in our previous study [17] where SFA was positively associated with $\mathrm{M}_{1} \mathrm{dG}$ adducts rather than PUFA. Overall, these results show that $\mathrm{M}_{1} \mathrm{dG}$ adducts analysis must be performed at an earlier time point in the dietary intervention in order to see a measurable effect.

\section{Trial Registration}

Cambridge Local Research Ethics Committee LREC01/ 055 .

\section{ACKNOWLEDGEMENTS}

Dr Ed Okello performed HPLC-Fluorescence analysis at The School of Biology, University of Newcastle upon Tyne. Dr Siobhan Higgins analyzed MDA in food at the Department of Nutrition, Glasgow University. Dr Peter Raggatt analyzed oestrogen at the Clinical Chemistry Department, Addenbrookes hospital, Cambridge. Miss Judith Wills and Mrs Valerie Church are thanked for provision and care of volunteers in the Dunn Human Nutrition Unit Volunteer Suite. Financial support: Dr Sharon Moore was supported by the Food Standards Agency (contract number: T01007).

\section{REFERENCES}

[1] Potter JD. Colorectal cancer: Molecules and populations. J Natl Cancer 1999; 91(11): 916-32.

[2] World Cancer Research Fund / American Institute for Cancer Research. Food, nutrition and the prevention of cancer: A Global Perspective. Washington DC: AICR 1997.

[3] World Cancer Research Fund / American Institute for Cancer Research. Food, nutrition, physical activity, and the prevention of cancer: a global perspective. Washington DC: AICR 2007.

[4] Shaw C, Blakely T, Sarfati D, Fawcett J, Peace J. Trends in colorectal cancer mortality by ethnicity and socio-economic position in New Zealand, 1981-99: one country, many stories. Aust N Z J Public Health 2006; 30(1): 64-70.

[5] Maskarinec G, Noh JJ. The effect of migration on cancer incidence among Japanese in Hawaii. Ethnicity Dis 2004; 14(3): 431-9.

[6] Moradi T, Delfino RJ, Bergstrom SR, Yu ESH, Adami HO, Yuen J. Cancer risk among Scandinavian immigrants in the US and Scandinavian residents compared with US whites, 1973-89. Eur J Cancer Prev 1998; 7(2): 117-25.

[7] Giovannucci E, Goldin B. The role of fat, fatty acids, and total energy intake in the etiology of human colon cancer. Am J Clin Nutr 1997; 66(6): S1564-71.

[8] Ozdemirler G, Pabuccuoglu H, Bulut T, Bugra D, Uysal M, Toker G. Increased lipoperoxide levels and antioxidant system in colorectal cancer. J Cancer Res Clin 1998; 124(10): 555-9.

[9] Hendrickse CW, Kelly RW, Radley S, Donovan IA, Keighley MRB, Neoptolemos JP. Lipid-peroxidation and prostaglandins in colorectal-cancer. Br J Surg 1994; 81(8): 1219-23.

[10] Basu AK, Marnett LJ. Unequivocal demonstration that malondialdehyde is a mutagen. Carcinogenesis 1983; 4(3): 331-3.
[11] Mukai FH, Goldstein BD. Mutagenicity of malonaldehyde, a decomposition product of peroxidized polyunsaturated fatty-acids. Science 1976; 191(4229): 868-9.

[12] Niedernhofer LJ, Daniels JS, Rouzer CA, Greene RE, Marnett LJ. Malondialdehyde, a product of lipid peroxidation, is mutagenic in human cells. J Biol Chem 2003; 278(33): 31426-33.

[13] Marnett LJ. DNA adducts of $\alpha, \beta$-unsaturated aldehydes and dicarbonyl compounds. In: Hemminki K, Dipple A, Shuker DEG, Kadlubar FF, Segerbäck D, Bartsch H, Eds. DNA adducts: identification and biological significance. Lyon: IARC Scientific Publications 1994; pp. 151-63.

[14] Everett SM, Singh R, Leuratti C, et al. Levels of malondialdehydedeoxyguanosine in the gastric mucosa: Relationship with lipid peroxidation, ascorbic acid, and Helicobacter pylori. Cancer Epidem Biomark 2001; 10(4): 369-76.

[15] Fang JL, Vaca CE, Valsta LM, Mutanen M. Determination of DNA adducts of malonaldehyde in humans: Effects of dietary fatty acid composition. Carcinogenesis 1996; 17(5): 1035-40.

[16] Nair J, Vaca CE, Velic I, Mutanen M, Valsta LM, Bartsch H. High dietary omega- 6 polyunsaturated fatty acids drastically increase the formation of etheno-DNA base adducts in white blood cells of female subjects. Cancer Epidem Biomark 1997; 6(8): 597-601.

[17] Leuratti C, Watson MA, Deag EJ, et al. Detection of malondialdehyde DNA adducts in human colorectal mucosa: Relationship with diet and the presence of adenomas. Cancer Epidem Biomark 2002; 11(3): 267-73.

[18] Bingham SA. Dietary assessments in the European prospective study of diet and cancer(EPIC). Eur J Cancer Prevent 1997; 6(2):118-24.

[19] Sanderson MJ, White KLM, Drake IM, Schorah CJ. Vitamin E and carotenoids in gastric biopsies: The relation to plasma concentrations in patients with and without Helicobacter pylori gastritis. Am J Clin Nutr 1997; 65(1): 101-6.

[20] Wang MY, Liehr JG. Induction by estrogens of lipid-peroxidation and lipid peroxide-derived malonaldehyde-DNA adducts in male syrian-hamsters - role of lipid-peroxidation in estrogen-induced kidney carcinogenesis. Carcinogenesis 1995; 16(8): 1941-5.

[21] Lewin MH, Bailey N, Bandaletova T, et al. Red meat enhances the colonic formation of the DNA adduct O-6-carboxymethyl guanine: Implications for colorectal cancer. Cancer Res 2006; 66(3): 185965.

[22] Department of Health. Dietary reference values for food energy and nutrients for the United Kingdom. Report of the panel on dietary reference values of the committee on medical aspects of food policy. Report on health and social subjects No. 41. London: HMSO 1991.

[23] Leuratti C, Singh R, Lagneau C, et al. Determination of malondialdehyde-induced DNA damage in human tissues using an immunoslot blot assay. Carcinogenesis 1998; 19(11): 1919-24.

[24] Sevilla CL, Mahle NH, Eliezer N, et al. Development of monoclonal antibodies to the malondialdehyde- deoxyguanosine adduct, pyrimidopurinone. Chem Res Toxicol 1997; 10(2):172-80.

[25] Sanchez-Escalante A, Torrescano G, Djenane D, Beltran JA, Roncales P. Stabilisation of colour and odour of beef patties by using lycopene-rich tomato and peppers as a source of antioxidants. J Sci Food Agr 2003; 83(3): 187-94.

[26] Buege JA, Aust SD. Microsomal lipid peroxidation. Biomembranes C 1978; 52: 302-10.

[27] Therasse J, Lemonnier F. Determination of plasma lipoperoxides by high-performance liquid-chromatography. J Chromatogr-Biomed 1987; 413: 237-41.

[28] Welch AA, Bingham SA, Ive J, et al.. Dietary fish intake and plasma phospholipid $n-3$ polyunsaturated fatty acid concentrations in men and women in the European Prospective Investigation into Cancer-Norfolk United Kingdom cohort. Am J Clin Nutr 2006; 84: 1330-9.

[29] Steghens J-P, van Kappel AL, Riboli E, Collombel C. Simultaneous measurement of seven carotenoids, retinol and [alpha]tocopherol in serum by high-performance liquid chromatography. $\mathrm{J}$ Chromatogr B Biomed Sci 1997; 694(1): 71-81.

[30] De Kok T, Zwingman I, Moonen EJ, et al. Analysis of oxidative DNA damage after human dietary supplementation with linoleic acid. Food Chem Toxicol 2003; 41(3): 351-8.

[31] Simopoulos AP. Essential fatty acids in health and chronic disease. Am J Clin Nutr 1999; 70(3): 560S-9. 
[32] Davidson LA, Nguyen DV, Hokanson RM, et al. Chemopreventive $n-3$ polyunsaturated fatty acids reprogram genetic signatures during colon cancer initiation and progression in the rat. Cancer Res 2004; 64(18): 6797-804.

[33] Zhou XF, Taghizadeh K, Dedon PC. Chemical and biological evidence for base propenals as the major source of the endogenous $\mathrm{M}(1) \mathrm{dG}$ adduct in cellular DNA. J Biol Chem 2005; 280(27): 25377-82.

[34] Plastaras JP, Riggins JN, Otteneder M, Marnett LJ. Reactivity and mutagenicity of endogenous DNA oxopropenylating agents: Base propenals, malondialdehyde, and N-epsilon- oxopropenyllysine. Chem Res Toxicol 2000; 13(12): 1235-42.
[35] Hoberg AM, Otteneder M, Marnett LJ, Poulsen HE. Measurement of the malondialdehyde-2 '-deoxyguanosine adduct in human urine by immunoextraction and liquid chromatography/atmospheric pressure chemical ionization tandem mass spectrometry. J Mass Spectrom 2004; 39(1): 38-42.

[36] Otteneder MB, Knutson CG, Daniels JS, et al. In vivo oxidative metabolism of a major peroxidation-derived DNA adduct, M(1)dG. Proc Natl Acad Sci USA 2006; 103(17): 6665-9.

[37] Knutson CG. Metabolism and elimination of the endogenous DNA adduct, 3-(2-deoxy-beta-D-erythropentofuranosyl)-pyrimido[1,2alpha]purine-10(3H )-one, in the rat. J Biol Chem 2007; 282 36257-64.

(C) Moore et al.; Licensee Bentham Open.

This is an open access article licensed under the terms of the Creative Commons Attribution Non-Commercial License (http://creativecommons.org/licenses/by-nc/3.0/) which permits unrestricted, non-commercial use, distribution and reproduction in any medium, provided the work is properly cited. 